\section{PREVENTION OF FIFTH METATARSAL BONE STRESS FRACTURE IN YOUTH JAPANESE SOCCER PLAYERS}

1,2,3,4 Yoshitomo Saita, ${ }^{1,2,3}$ Nagao Masashi, ${ }^{1,3}$ Kobayashi Yohei, ${ }^{1}$ Kobayashi Keiji, 'Wakayama Takanori, ${ }^{1,2} \mathrm{Ikeda}$ Hiroshi. 'Department of orthopedics and sports medicine, Juntendo university, Tokyo, Japan; 'FIFA medical centre of excellence in Tokyo, Tokyo, Japan; ${ }^{3}$ Jones fracture research group, Tokyo, Japan; ${ }^{4}$ Japan sports injury prevention association, Iwaki, Japan

\subsection{6/bjsports-2021-IOC. 166}

Background The stress fracture of the fifth metatarsal bone (5MT) frequently occurs in youth soccer players in Japan, and it is very important issue to prevent this fracture.

Objective To confirm whether preventive intervention successfully reduced the incidence of 5MT

Design Observational cohort study to compare the occurrence of 5MT before (2003-2009) and after (2010-2016) intervention.

Setting One football (soccer) club in Japan.

Patients (or Participants) One hundred and fifty-nine elite Japanese youth (under 18) football (soccer) players belonged to one football club from 2003 to 2016. The incidence of 5MT were compared before intervention ( 7 years) and after intervention (7 years).

Interventions (or Assessment of Risk Factors) We proposed the prevention strategy on 2010 based on our clinical experiences and past publications regarding with 5MT (https://saita0617. wixsite.com/jones/english-ver).

Main Outcome Measurements Incidence of 5MT.

Results The incidence of 5MT before intervention was 11 cases, while it was decreased to 2 cases after intervention. The hazard ratio for the incidence of 5MT was 3.99 (95\% CI: 1.06 to $15.05, \mathrm{p}=0.04$ ) in the 88 soccer players prior to prevention compared with 71 players post prevention.

Conclusions The prevention intervention was effective to reduce the incidence of 5MT in youth Japanese football players.

\section{ACUTE EFFECTS OF SMALL-SIDED GAMES ON THE LOWER LIMB FUNCTIONAL ASYMMETRY IN YOUNG SOCCER PLAYERS}

\footnotetext{
${ }^{1,2}$ Italo Sannicandro, ${ }^{2}$ Giacomo Cofano, ${ }^{2}$ Anna Rosa Rosa, ${ }^{2}$ Paolo Traficante, ${ }^{2}$ Andrea Piccinno. 'Department of Clinical and Experimental Medicine, University, Foggia, Italy; ${ }^{2}$ Strength and conditioning soccer coach, Foggia, Italy
}

\subsection{6/bjsports-2021-IOC. 167}

Background Lower limb asymmetry is defined in relation to the observed performance differences (Bishop et al., 2018) and is found in athletes practicing different sports (Bishop et al., 2019\&2018). The Small-Sided Games (SSG) represent a specific form of exercise widespread in soccer training (Kunz et al., 2019). Some authors have described the acute effects of fatigue on hamstring strength in professional soccer players (Madison et al., 2019). In the literature there are no similar studies conducted on young soccer players.
Objective To verify if the SSG practice conditions lower limb asymmetry in U15 young players.

Design Within subject repeated measures design.

Setting Youth soccer

Patients (or Participants) $n=16$ young players (age: 14.1 \pm 0.6 ; weight: $58.5 \pm 7.4 \mathrm{~kg}$; height: $166.3 \pm 4.1 \mathrm{~cm})$.

Interventions (or Assessment of Risk Factors) The sample was evaluated before warm up (15 minutes), after 10 minutes of mastery ball and $4 \mathrm{vs} 4 \quad(3 \times 3$ minutes, rec.2' field:24x36m, with staff encouragement and 30 balls available) through Hop Test (HT), Side Test (ST), Crossover Test (CT), peak strength (PS) and hamstring eccentric average (in 5 repetitions) strength (EAS) by dynamometer (N3, Easytech, Italy).

Main Outcome Measurements Asymmetry value was calculated using the formula: Non-Dominant Leg/Dominant Leg x 100 (Ceroni et al., 2012).

Results The pre/post intervention comparison showed an increase in asymmetry in HT $(2.59 \pm 1.72 \%$ vs $12.35 \pm 4.23 \%)$, in ST $(3.79 \pm 2.21 \%$ vs $16.61 \pm 3.35 \%)$, in the CT $(2.75 \pm 2.52$ vs $10.98 \pm 7.16 \%)$, in the PS $(4.49 \pm 3.16$ vs $15.41 \pm 5.53 \%)$ and in the EAS $(3.93 \pm 2.48$ vs $20.09 \pm 5.25 \%)$. All differences were significant for $\mathrm{p}<0.0005$.

Conclusions The SSG training seems to determine a significant increase lower limb asymmetry values, most likely due to fatigue as described in professional soccer players (Madison et al., 2019). These values must be carefully evaluated by the coaches in the training scheduling in youth soccer.

\section{ACUTE FATIGUE EFFECTS AFTER SMALL-SIDED GAMES ON FUNCTIONAL ASYMMETRY AND SHORT SPRINT PERFORMANCE IN YOUNG SOCCER PLAYERS}

${ }^{1,2}$ Italo Sannicandro, ${ }^{2}$ Giacomo Cofano, ${ }^{2}$ Anna Rosa Rosa, ${ }^{2}$ Paolo Traficante, ${ }^{2}$ Andrea Piccinno. ${ }^{1}$ Department of Clinical and Experimental Medicine, University, Foggia, Italy; ${ }^{2}$ Strength and conditioning soccer coach, Foggia, Italy

\subsection{6/bjsports-2021-IOC.168}

Background Lower limb strength asymmetry (SA) is monitored to reduce the injury risk in the young player. Asymmetry values values greater than or equal to $15 \%$ indicate a potential injury risk (Noyes et al., 1991). Small-Sided Games (SSG) are widespread in youth training but not all load effects have been analyzed (Kunz et al., 2019).

Objective To describe the fatigue effects on lower limb SA values and sprint values after each SSG series.

Design Within subject repeated measures design.

Setting Youth soccer. Patients (or Participants) $n=16$ regional level young players $(12.1 \pm 0.9$ years, $43.8 \pm 8.3 \mathrm{~kg}, \quad 147.8$ $\pm 9.3 \mathrm{~cm})$

Interventions (or Assessment of Risk Factors) The sample was evaluated after the warm-up of 15 minutes and 10 minutes of mastery ball exercises, and at the end of each series (3) of 4vs4 (duration: 3 minutes, rec: 2 'field: $24 \times 36$ meters, with encouragement of staff and 30 balls available) through Hop Test (HT), Side Test (ST), Crossover Test (CT), 5 meters sprint $(5 \mathrm{M})$.

Main Outcome Measurements Asymmetry value was calculated using the formula: (Non-Dominant Leg/Dominant Leg)x100 (Ceroni et al., 2012).

Results The results are summarized as follows: 